\title{
Use of exemplification in ESL students' self-assessment reports: Can they help to argue better?
}

Lina Mukhopadhyay

School of English Language Education, The English and Foreign Languages University, India

Received: April 2020; Accepted: May 2020

\begin{abstract}
Self-assessment reports are a type of alternative assessment and provide a gateway of formative assessment by which learners get opportunities to reflect on their learning process and assess it, provided they are aware of their abilities and progress. In this exploratory study, we examine the self-assessment reports of 12 adult ESL learners enrolled in an Indian university programme where they assess the course content and language gains (reading and writing) from the course. Based on a mixed method of analysis, the learners were found to use exemplification to suit their discourse style. A quantitative analysis showed that the learners were using a variety of exemplification techniques like (i) brief examples with (a) phrases and (b) sentences; (ii) extended examples; and (iii) testimonials to support and argue for their assessments. Furthermore, the learners were found to use these different types of exemplification according to the levels of unity or coherence in their reports, which were at three levels - low (16\%), medium (50\%), and high unity (34\%). For instance, the presence of the first two subtypes of exemplification was found to be more frequent across the learners of low and medium unity whereas the last two types were more prevalent in the high text unity group of learners. A one-way goodness of fit chi-square test revealed that the two frequent sub-types were well distributed for the entire group as well as for the learners whose essays achieved low and medium unity while for the learners who achieved high unity the distribution was equal. Furthermore, a qualitative analysis of a few excerpts showed the types and purposes of using exemplification with $23 \%$ overt and $77 \%$ null markers; it was interesting to note that the null markers did not affect the communicative content of the reports as the learners were found to use other syntactic strategies to mark the presence of exemplification like listing of ideas and using wh-question markers preceding the ideas. A few instances of personalized anecdotal experiences showed that learners were using exemplification to substantiate their arguments at a high level. What is implied from this analysis is that such semi-formal self-assessment reports can be used for two purposes: to assess a course and document learner growth and orientation towards learning, and through the assessment task, trigger a linguistic gain such as develop argumentation skills in adult ESL learners.
\end{abstract}

Keywords: argumentation skills, self-assessment reports; exemplification; topic analysis; text unity

\section{INTRODUCTION}

Self-assessment reports are a type of alternative assessment and provide a gateway of formative assessment by which learners get opportunities to reflect on their learning process and assess it (Hargreaves et al. 2001), provided the learners are aware of their abilities and progress (Blanche, Merino 1989). Thus, from the information learners provide about themselves, teachers get to understand learners' responses to a course or learning, both cognitively and emotionally, and can use this tool to help learners monitor their own work (Birjandi, Hadidi 2012; Oscarson, Apelgren 2011). The reports also document learner growth (and their perceptions of growth)

* Correspondence: Lina Mukhopadhyay: linamukhopdhayay@efluniversity.ac.in; https://orcid.org/0000-0001-9448-4920 
and learner difficulties and it places them in charge of their growth in the age of modern education (Butler, Lee 2010). Though there is some amount of resistance to use this form of assessment to let learners formally grade themselves (Luoma, Tarnanen 2003), some research has gone into exploring the effectiveness of using this form of assessment to document learner goals and orientations towards language learning as a way of engaging through this tool of assessment that serves as feedback to both the learners and the teachers about learning outcomes (Balegazideh, Masoun 2014).

Self-assessment may be done through questionnaire-based scores and grades (Boud, Falchikov 1989; Oscarson, Apelgren 2011) or in the form of formative reports that are usually written (Matsuno 2009), but might be oral as well (Chen 2008; de Saint-Léger 2009). In this study, the focus is on formative written self-assessment reports. When learners write these reports, they need to reflect on what they have learnt (and not learnt), making them take charge of their learning, both for subject knowledge and language development (Paris, S. G., Paris A. H. 2001). Teachers, on the other hand, may use such reports to dig out learner attitudes and their opinion of the teacher, course and the teaching style (Blanche, Merino 1989). Teachers may even use them in writing courses to create scope for revision and redrafting (Sadek 2013; Oscarson, Apelgren 2011).

The advantages of self-assessment reports stated earlier are widely acknowledged (Bachman 2000; Hargreaves et al. 2001). However, the writing of these reports has an advantage, which is not the primary objective of the reports: Self-assessment reports have the possibility to create language gains provided teachers analyze such reports for genre-based moves like students' ability to elaborate upon a claim citing examples. When we write an assessment of a course, a movie, a restaurant, what we need is the assessment per se and some evidence to support the assessment as demonstrated in Box 1 and 2 below:

Cafe Ludus, situated on the top floor of Saket's posh MGF mall, is bound to take you down the nostalgic road of school days as the menu is made to resemble a scrapbook with the dishes and beverages doodled in white chalk, the bar area is reminiscent of the chemistry laboratory, the sitting area has low wooden benches, and a reading corner where magazines are slung along hangers.

Box 1: Assessment of a Restaurant

If this is the structure of an assessment of restaurant (Box1) and of a movie (Box 2), it is not different from putting forth an argument with a claim and the support for it. Keeping this similarity of assessment and argumentation in mind, we assume that a self-assessment report should and will help learners to form and structure arguments better. But such a linguistic gain afforded by self-assessment reports is not very well known.
Therefore, apart from the well-known advantages of self-assessment reports in a curriculum, the learning of argumentation is an added advantage, an advantage which is observable, but often not explainable. However, such a scope presented by such reports has not been examined previously. Therefore, in this paper I look at the language learning gains such as writing convincing argumentative texts afforded by writing self-assessment reports in a group of adult ESL learners.

\section{ESL WRITING \& SKILLS OF ARGUMENTATION}

In higher education, learners often need to write argumentative texts on different topics and in the form of term papers and reports. However, research on SL writing shows that learners often fail to adopt an appropriate argumentative style because of poor writing instruction and inadequate feedback from teachers (Hinkel 2001). Mismatch between rhetorical styles in learners' L1 and $L 2$ has also been used as a reason for poor argumentation skills in ESL learners, like in Chinese learners of English (Cheng, Chen 2009) and French learners of English (Paquot 2008) to cite a few examples.

Conventional methods of building an argument is to first present a claim and then substantiate it with supporting details and examples. Often, a writer needs to preempt counter arguments and also refute them. In an expert writer's texts, we can expect to find the interplay of argument-counter argument neatly woven in the text, without the counter arguments being stated explicitly in the text, and following in line with the Aristotelian rhetorical style of argumentation (Connor 1996).

One prominent component of a good argumentative text is providing examples as evidences which support the main claim because they provide a valid opportunity to the writer to present details and make an argument clear and convincing (Smalley, Ruetten 2000). Exemplification, therefore, can serve a variety of communicative functions or purposes-support a thesis statement,

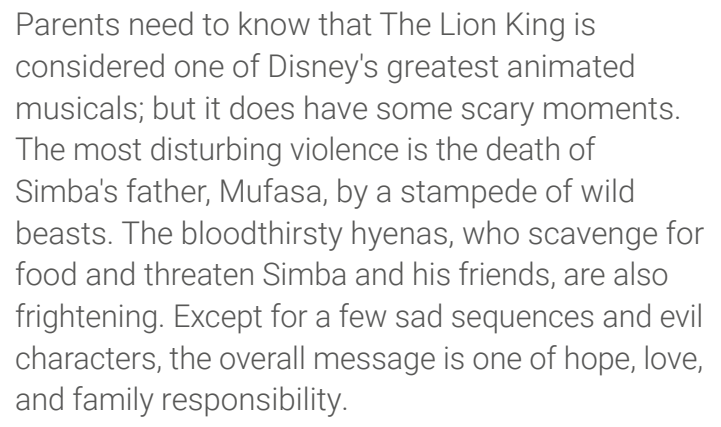

Box 2: Assessment of a Movie

illustrate/clarify a point, reinforce an idea, and present a vivid analysis of a situation/idea through past recounts (Hinkel 2001). The use of exemplification also involves self-expression and creativity. Overt functional markers can often signal use of examples: such as, like, namely, for example, for instance, and e.g./eg. 


\section{TYPES AND PURPOSES OF EXEMPLIFICATION}

Given below is a list of different types and functions of examples that can be at a writer's disposal (Halliday, Hasan 1976; Biber et al. 2004):

A) Brief examples are mentioned in passing to illustrate a point, often presented as a list of words or phrases, and connected with an additive marker (e.g. and).

B) Extended examples elaborate a point and can be anecdotes, descriptions, personal recounts, a typical case description, a hypothetical idea/ case, and others.

C) Testimonials consist of expert opinion on a particular idea; they are often presented as short quotes from another author in one's essay.

D) Based on the data we looked at in this study, a fourth category of using exemplification was found: Ideas can be presented as a list of sentences as examples to illustrate a claim (e.g. see Box 2 above: sentences 2 and 3 ). These are brief examples presented at the sentence level.

Although ESL learners often get to read texts that use the technique of exemplification to build arguments (Hinkel 2001; Smalley, Reutten 2000), research shows that they often fail to represent a similar style in their writing (Hvitfeldt 1992; Hinkel 2001). If learners use exemplification, they tend to use a rather subjective style by presenting too many personal experiences as examples. Such frequent inclusions of personal recounts lower the levels of formality and objectivity required in academic writing (Paquot 2008). Why do learners fail to replicate a style of writing which they often read? One explanation could be that when learners read various types of academic texts like articles, experimental studies, reviews and argumentative papers, they primarily read for content. In the process, they get the gist of the text but often fail to observe how an author builds a line of argumentation in the text. This failure to notice and infer from an author's style of writing how an argument can be established could be a reason for underrepresenting exemplification in ESL writing.

In Indian universities, although the focus is on content development through English as the medium of instruction, teachers use content-based learning and assessment approach that is mostly summative (Meghanathan 2015; Brinkmann 2018). So alternative assessments like self-assessments are hardly ever explored to document learner growth or orientation towards learning or learner awareness that they can talk about their own abilities and participate in a collaborative assessment of their growth (Clark 2003). In addition to this, content or language courses which require learners to engage in academic writing are not designed in a manner to support growth in writing knowledge, though most of the tasks learners get to do have argumentation as an integral component (Birjandi, Siyyari 2010). So, this paper explores the knowledge of argumentation skills in adult ESL learners studying in an Indian university and the extent to which they are able to use their skills through use of appropriate moves such as presenting a claim and elaborating it with examples in their written self-assessment reports to document their learning outcomes and future goals of learning.

In this paper, I present an exploratory study from a classroom based in-depth research on a small group of adult ESL learners who were enrolled in a university course at the time of the study. Their self-assessment reports will be descriptively and qualitatively analyzed to show whether they are able to use exemplification to argue while writing the self-assessment reports. The research questions (RQs) addressed in this study are: 1) Do ESL learners use exemplification in their self-assessment reports?

2) Is the frequency of use and type of exemplification guided by the level text unity/coherence?

\section{THE STUDY \\ SUBJECTS}

12 learners ( 6 male, 6 female), aged between 20 and 27 years, enrolled in a course on Language Testing run as part of the first semester of $\mathrm{PhD}$ programme in The EFL University, Hyderabad, participated in the study. For most of their academics related work, the learners used English, and all of them had a Master's degree in English. Their proficiency levels in English ranged from low intermediate (B1) to upper intermediate (B2). This was ascertained based on their reading abilities and written work submissions assessed by the tutor in the course. Outside class, these learners quite frequently engaged in academic discussions and social communication in English because they were living on the university campus during this programme. As they had different L1s, English quite naturally was the lingua franca of this group. This enhanced their oral skills and argumentation skills in the target language as they got frequent opportunity even outside class to practice such skills, at least orally.

\section{TASK AND PROCEDURE}

This study resulted from a six-month-long classroom-based research conducted on the 12 learners when they were enrolled in the Language Testing course. As an end semester assessment, the learners had to work on a test development project. Along with this they were also asked to submit self-assessment reports based on the following prompt:

Your academic language skills in English and content knowledge has developed by doing this project. Do you agree or disagree with this statement? If an end term examination had been used in place of this project, would you have benefitted equally? Justify your stance using relevant examples. Write your response in about 450-800 words.

Throughout the course, the learners were sensitized about the development of argumentation in writing and the significance of using relevant examples to better 
express content understanding. They were made to write several response papers where they were advised to use exemplification. In the feedback on these papers, the (under)use of exemplification was commented upon. It was expected that the feedback given might be beneficial in helping learners use appropriate exemplification techniques.

\section{METHOD OF DATA ANALYSIS}

The self-assessment reports were examined to look into text coherence or text unity and the frequency, types and purposes of examples used.

It was expected that learners would use argumentation as a response to the prompt provided. So, text coherence would be built on the basis of certain key ideas or moves. For instance, the texts would need to have a main claim that language skills have/ have not improved. This is an effect which would be based on a cause like 'working on the end term project'. Some examples would have to be used to substantiate this cause and effect relationship. The learners would also have to refute a counter claim that an end semester exam would not play a similar beneficial role in improvement of language skills. The presence of these moves in learner texts were examined thorough topic analysis adapted from Watson Todd et al. (2004) and was counted based on the presence of the following topic moves:

Move 1: Present a claim as a topic sentence

Move 2: Justify it with evidences/examples that are reliable and valid

Move 3: Refute any opposing claim/ idea

Move 4: Conclude by connecting with the main claim

Note that these moves are generic in nature in keeping with the structure of the genre that is self-assessment reports. The learners were made aware of the structure based on the instruction they received to write the reports. So the moves counted are to show genre specific knowledge of use of exemplification. Hence the moves are a presentation of list of topics or features that are generalizable. In this regard, we predict that moves one, three and four are more salient as information is foregrounded as introduction, elaboration and conclusion; so they are likely to be more frequently used across learners while move three would depend on learner ability to establish a counter argument with corresponding exemplification. Therefore, this is more challenging and is likely to be used only by learners who have a higher level of writing knowledge.

Furthermore, the range of examples used was counted according to the frequency count of types (e.g. brief examples at phrase level, brief examples at sentence level, extended examples, and testimonials of experts), and their communicative functions or purposes (to clarify, to reinforce, to personalize) (Halliday, Hasan 1976; Biber et al. 2004).

\section{FINDINGS}

A mixed method of analysis (Dorneyei 2007) is adopted for this paper to report the findings. So, a quantitative and qualitative presentation of the use of exemplification in the narrative self-assessment reports of the 12 adult ESL learners is presented to provide evidence for each research question.

\section{RQ1: DO ESL LEARNERS USE EXEMPLIFICATION IN THEIR SELF-ASSESSMENT REPORTS?}

First, we present a descriptive analysis of the performance of the learners. The overall performance of the learners-(i) text length, (ii) use of overt exemplification markers and (iii) type token ratio of overt markers to text length-is reported in Table 1:

\begin{tabular}{|c|c|c|c|}
\hline & $\begin{array}{c}\text { Text } \\
\text { length }(\boldsymbol{M})\end{array}$ & $\begin{array}{c}\text { Number of overt } \\
\text { exemplification } \\
\text { markers }\end{array}$ & $\begin{array}{c}\text { Type token } \\
\text { ration }\end{array}$ \\
\hline Mean (m) & 443.83 & 1.08 & 0.003 \\
\hline $\begin{array}{c}\text { Standard } \\
\text { deviation (SD) }\end{array}$ & 15.51 & 0.14 & 0.006 \\
\hline
\end{tabular}

Table 1: Overall performance on the self-assessment report \& use of exemplification

To write the self-assessment narrative reports, the learners have used a total number of 5326 words. The range of text length across the 12 learners was between 395 to 754 words and the group performance was good $(M=443.83 ; S D=15.51)$ because all of them fulfilled the text length criteria of the task.

The use of total number of overt exemplification markers was only 13 . So the ratio of use of overt exemplification markers was very low: .03\%, which is realistic given the fact that in an essay a writer is not likely to use many examples and even if he/she uses examples, they might not always signal them with an overt functional marker (e.g. for instance, such as, like, and so on). The spread and purposes of using actual exemplification is discussed in a section below.

Let us now look at an analysis of the nature of topic moves the learners have attempted to write in the report and the level of text unity or coherence they might have achieved thereby. This is because we need to analyze the texts for their quality of development of content and coherence and see the extent to which this controls the use of exemplification in adult ESL writing. This is a necessary step to answer RQ2.

\section{TOPIC ANALYSIS OF SELF-ASSESSMENT REPORTS} The findings on topic analysis are presented in Table 2:

Table 2 summarizes the group mean scores on using the topic moves. The table shows that all the learners were successful in using the first two moves, that is, 
make a claim and substantiate it with exemplification $(M=1 ; S D=0)$. Most of them were also able to use the fourth move which is to conclude their write-up $(M=0.83$; $S D=0.38)$. Only a third of the learners were not able to use the third move i.e., refute an opposing claim $(M=0.33 ; S D=0.49)$.

\begin{tabular}{|c|c|c|}
\hline & Mean (M) & SD \\
\hline Move 1 & 1 & 0 \\
\hline Move 2 & 1 & 0 \\
\hline Move 3 & 0.33 & 0.49 \\
\hline Move 4 & 0.83 & 0.38 \\
\hline
\end{tabular}

Table 2: Mean distribution of Moves

The learners who have included all the four moves have achieved a higher level of text unity, and thereby argumentation, than those who have included only two or three moves. Three groups of learners emerged based on the total frequency count of use of the four moves in writing the self-assessment reports. A group-wise performance on building text unity is shown in Figure 1 below:

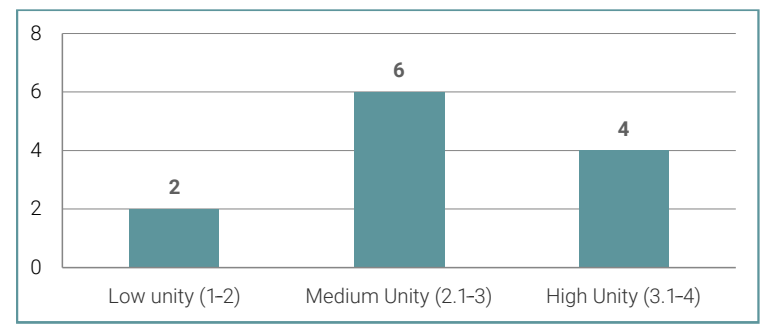

Figure 1: Group-wise Range of Unity Achieved

The learners who were in the low unity group (2) presented the first two moves only. Learners in the medium unity group (6) used the first two moves and the last move to conclude their texts in a formal manner. Learners in the high unity group (4) used all the four moves in that they could make a claim (move 1), use examples to substantiate it (move 2), refute a counter claim (move 3) and draw a logical conclusion about the main claim (move 4) and displayed a high level of writing knowledge in ESL (Hinkel 2001). In all, based on the findings from Table 2 and Figure 1, RQ 1 is validated to be true: The learners use exemplification, though its usage is not uniform across learners.

\section{RQ2: IS THE FREQUENCY OF USE \& TYPE OF EXEMPLIFICATION GUIDED BY THE LEVEL TEXT UNITY/COHERENCE?}

Now that we have regrouped the learners into three levels of text unity or coherence they have achieved, let us examine if the level of text unity is linked to the well-formed presence of exemplification. In other words, on the basis of a qualitative analysis we now report the different types and purposes of using exemplification according to levels of text unity.
Given below are sample extracts from the self-assessment reports. We present the extracts as they were written. No attempts at editing the scripts for language and mechanics were made. Through these instances of use of exemplification we can examine the types of exemplifications used and the purposes for which they have been employed for.

In (1), an excerpt from a learner in the high unity group, we see an instance of a well-embedded extended form of exemplification with an overt marker to establish an argument and draw a link to what can be done in future and complete discussing the claim:

(1) It helped me to understand a good piece of writing: At first, argument should be stated and then (secondly) followed by substation to reason out the argument or thesis stated. For example, the reading from Shohamy (2001), Voice of the test takers, stated various voices on the effects of the tests from real life experiences of the test takers. The real life experiences of the test takers give first hand data to strengthen the argument. I feel that I too should quote the voice of my target group learners in my research in order to substantiate my hypotheses. (SHPR 01)

Another learner from the high unity group, attempted to go beyond the format of exemplification and gave examples from her personal experience to elaborate how she used written feedback (given on her assignments) to improve her writing skills (example 2):

(2) The development of the language skills was possible because of the feedback we got for each response paper. I used the feedback I got for the assignments to set short term goals. When I got suggestions to improve certain areas of my writing, I used to make sure that I would get that aspect correct in the next response paper. For example, I made a mistake while citing the references as I haven't included the chapter that is used for the assignment. This was pointed out in my first response paper and after this I thought I shouldn't make this mistake again. So I could work in bits thereby developing my language skills gradually. (SHR 10)

A third learner from the high unity group has used an anecdotal experience as an example to strengthen and elaborate upon his point:

(3) End term exams encourage us, for the cramming of the subject matter. By saying this I do not intend to take all the credits away from end-term exams. They (the end-term) exams also have their advantages (utility). An end term exam would have tested our theoretical knowledge about the various different necessary aspects of testing like the five cardinal principles and the like. But by taking an end term we don't get to do things practically. It becomes very much same like 
reading the rules (books) on swimming without actually diving into the pool. For an instance in the end tem test we could have been asked to write the qualities of a good multiple choice item or at the most to try and construct one. But by doing the project we not only constructed items but assembled them as a unit and gave them to a specific group of test-takers. The test-takers took the test and we could evaluate their level of proficiency in English. Thus by taking up the project we could complete the 360 degree circle of testing without missing any single stage. (MUKA 11)

(4) and (5) are excerpts from medium unity group where the learners have used exemplification at a sentence level but well embedded to explain a viewpoint and make a link to the learners' self-assessment of developing their language skills by way of using this study skill:

(4) This project helped me to develop my study skills... It helped me to do research about particular topic. For example in the project I prepared some questions regarding grammar. So it helped me a lot to refer different materials and research about the grammar. This helped me to develop my language skills like reading and writing. (VILX 05)

(5) We benefitted tremendously from this project as we learnt unlimited crucial things about testing. Some of the things we learned are: how to work in a group, how to prepare; administer and analyze tests, we realized why it is essential to be friendly and flexible with the test takers and how to be so, how to make apt MCQs, what does a score mean. We also learned why time management is essential for test designers in designing tasks and how to do so. (VAS 02)

In (5) the claim is stated clearly: We benefitted tremendously from this project. Exemplification is signaled by an overt marker 'some' and five brief examples at phrase level are presented to support this claim: (a) how to work in a group, (b) how to prepare; administer and analyze tests, (c) we realized why it is essential to be friendly and flexible with the test takers, (d) how to make apt MCQs, and (e) what does a score mean. There is one brief example at sentence level where the learner talks about the idea of time management.

Many learners used a listing format, where the main claim is followed by a listing of what these language gains are. These are examples where a listing format of exemplification or brief exemplification is used:

(6) Following the conventions like using standard font (Times New Roman), font size (12), italicizing, capitalizing, punctuating, using bold letters and other technical things like working on MS Word and Excel etc. are properly mastered in the course of doing project. (SHPR 01)
Some learners used the listing type of exemplification or brief exemplification without any overt marking to signal this discourse strategy:

(7) The academic reading skills I have developed include how to comprehend content, identify different knowledge and experiences, identify the line of argumentation and examples used to substantiate my arguments, to develop my opinion on the text, and how to justify my opinion. (VAS 02)

(8) The study skills this course has helped me to improve are referencing, note making, researching a particular topic, etc. (VAS 02)

(9) The project have also helped us how to create test items, what to choose which item and which items are appropriate and the distractor analysis chart has again given feedback of which items are easy and difficult and what are the appropriate methods to be taken into account. (KAD 04)

(10) When we had to design and construct the test items, we referred several books, newspapers, journals to get the suitable texts for our target group. Now we know which material has which authentic text. This has improved my reference skills a lot. (SAG 09)

What we notice is that the lack of exemplification markers in (7-10) does not interfere with the communicative value or coherence building in the text. Note that in (9 and 10) while the overt markers are not used, the learners use a syntactic strategy of inserting wh-question markers to create the sense of exemplification-a style often adopted in academic writing.

When we looked at the explicit signaling of exemplification, an interesting trend was observed. It was found that the learners in the medium text unity and high text unity group used explicit signals: for example, such as, like. In contrast, learners who showed low text unity often failed to signal exemplification. They listed the examples (e.g., SWA 5 in example (3) given below) one after another along with the main ideas that seriously affected the readability of the texts. For instance, in the following text, examples are presented but not well signaled. The main claim is italicized, and the exemplification underlined and numbered $(i-v)$ :

(11) TD project was also useful to improve our academic writing skills as well. The evidence for this statement is our project report that we have written. In (i) data interpretation personally I have learnt a lot from that. (ii) Summarizing the results (iii) justifying the claims by giving examples, and (iv) paraphrasing the main ideas of researchers in the report etc, were useful. All the academic writing skills that we have followed during the report writing are really very useful for us in (v) writing our research dissertation. (SWA 11) 


\begin{tabular}{|c|c|c|c|}
\hline & Examples used & $\begin{array}{c}\text { Brief examples } \\
\text { at phrase level }\end{array}$ & $\begin{array}{c}\text { Brief examples } \\
\text { at sentence level }\end{array}$ \\
\hline Total & 58 & 33 & 25 \\
Mean (M) & 4.83 & 3.00 & 2.08 \\
$(S D)$ & $(1.81)$ & $(1.27)$ & $(1.49)$ \\
\hline
\end{tabular}

Table 3: Frequency of Types of Exemplification Used

\begin{tabular}{|c|c|c|c|c|c|c|}
\hline $\begin{array}{c}\text { Total Examples } \\
\text { used }\end{array}$ & $\begin{array}{c}\text { Brief } \\
\text { examples }\end{array}$ & $\begin{array}{c}\text { Extended } \\
\text { examples }\end{array}$ & $\boldsymbol{d f}$ & $\mathbf{t}$ & P value & $\begin{array}{c}\text { Standard error } \\
\text { of difference }\end{array}$ \\
\hline $\begin{array}{c}3.83 \\
(1.81)\end{array}$ & $\begin{array}{c}3.00 \\
(1.27)\end{array}$ & $\begin{array}{c}2.08 \\
(1.49)\end{array}$ & 22 & $\begin{array}{c}1.62, \\
n . s\end{array}$ & 0.11 & 0.56 \\
\hline
\end{tabular}

Table 3.1: Differences in use of brief and extended examples

So in the above eleven instances we observe that learners have used exemplification as a discourse marker and a strategy to explain a point as in $(1,2,3)$, to inform about the course details as in $(4,5)$ by using exemplification as a sentence and then linking it to a key idea, or to list ideas with or without overt exemplification markers (6-11). All the styles used are being guided by the requirement of the discourse content and the style of presentation. But the very ability to use exemplification is a move to elaborate upon points, which this learner group have been able to well achieve through the task of self-assessment reports. In sum, the findings from the topic analysis and types of purposes of exemplification show us that all the learners have used exemplification appropriately, that is to justify and elaborate the main claim of their self-assessment reports.

\section{FREQUENCY OF TYPES OF EXEMPLIFICATION USED IN SELF-ASSESSMENT REPORTS}

We now turn to the distribution of the two types of exemplification-brief examples at phrase level and brief examples at sentence level. Only one instance each of the third and fourth types - extended and testimonial were found. Therefore, we dropped these two types from this analysis. Table 3 summarizes the findings on the distribution of two types of exemplification:

Column one of Table 3 presents the total number of occurrences of exemplification used in the texts (12). All the learners have used examples in their self-assess-ment reports $(M=4.83 ; S D=1.81)$ with a combination of brief examples at phrase level and brief examples at sentence level. Table 3.1 shows that the difference in use of brief and extended examples is not significant ( $d f=1,22 ; t=1.62, p=0.11$, not significant).

Even though the use of brief examples at phrase level (33) was more frequent than the use of brief examples at sentence level (25), a one tailed chi-square test of goodness of fit showed that the difference was not significant, $\times 2(1, N=12)=1.10, p=.29$. This means that two types of examples at two levels of discourse-phrase level and sentence level-were well distributed across learner responses.

Specifically in brief examples at sentence level, it was found that learners used personal recounts (15) more than descriptions of general or typical ideas (10). Since the learners had to report on personal gains experienced during the course, they quite naturally used personal recounts to elaborate upon their claims thereby justifying its higher use over the other types.

It would be interesting to look at how the ranges of consolidated frequency counts on topic analysis interact with the type of exemplification used. Table 4 presents details of this interaction:

\begin{tabular}{|c|c|c|}
\hline Range & $\begin{array}{c}\text { Brief examples } \\
\text { at phrase level }\end{array}$ & $\begin{array}{c}\text { Brief examples } \\
\text { at sentence level }\end{array}$ \\
\hline $\begin{array}{c}1-2 \\
\text { (low unity) }\end{array}$ & 5 & 1 \\
\hline $\begin{array}{c}2.1-3 \\
\text { (medium unity) }\end{array}$ & 15 & 11 \\
\hline $\begin{array}{c}3.1-4 \\
\text { (high unity) }\end{array}$ & 13 & 13 \\
\hline
\end{tabular}

Table 4: Interaction between Range of Unity and Type of Exemplification

A one tailed chi-square test of independence showed that the difference in use of (a) brief examples at phrase level and (b) brief example at sentence level in between the three groups was not significant, $\times 2(2, N=12)=2.22$, $p=.32$, implying that the two types of examples were well distributed across the three levels of learners who achieved low, medium, and high unity or coherence in their self-assessment reports.

In Table 4 we also observe that the use of brief examples at sentence level increases as the level of text unity increases in the learners. However, a one tailed chi-square test of goodness of fit reveals that the difference in use of these two types of exemplification is not significant in 
either the low unity group, $\times 2(1, n=2)=2.66, p=.10$ or the medium unity group, $\times 2(1, n=6)=0.61, p=.43$. These findings again point to the fact of well distributed example types across low and medium unity levels. In contrast, the high-level unity group of the four learners out of the twelve used both types equally effectively, indicating that their use of exemplification was not only more well-formed but also equally stable across the two types.

The findings on interaction between the types of exemplification used and the range of unity show that learners who have attained higher text unity tend to use brief examples at sentence level very effectively (refer to examples 2, 4, and 5 above). These examples elaborate the main claim or supporting claims better than giving brief examples as list of phrases. So, at higher levels of writing ability, signaled through higher scores on text unity, examples are used in an elaborate manner to establish the validity of a claim in a convincing manner.

\section{USE OF OVERT EXEMPLIFICATION MARKERS}

Table 5 presents the findings on the use of explicit markers to signal the presence of examples in learner texts:

\begin{tabular}{|c|c|c|c|}
\hline & $\begin{array}{c}\text { Examples } \\
\text { used }\end{array}$ & $\begin{array}{c}\text { Overt Markers } \\
\text { used }\end{array}$ & Text Length \\
\hline Total & 58 & 13 & 5326 \\
Mean $(M)$ & 4.83 & 1.08 & 443.83 \\
SD & $(1.81)$ & $(1.11)$ & $(1.55)$ \\
\hline
\end{tabular}

Table 5: Use of Overt Exemplification Markers

On an average, the length of learner texts was approximately 444 words. The texts on an average had 4 examples of which only one marker was overtly signaled; so only a quarter of the examples (23\%) had overt markers while $77 \%$ had null markers; learners used other syntactic strategies to signal exemplification (refer to excerpts 7-10). The overt markers used, and their corresponding frequency of occurrence, is as follows: for example (5), such as (2), like (2), in terms of (2), another example (1), for instance (1). The use of for example as a marker of exemplification has been found to be used more frequently by ESL/EFL learners in comparison to the marker 'for instance' as reported in a study by Cheng,

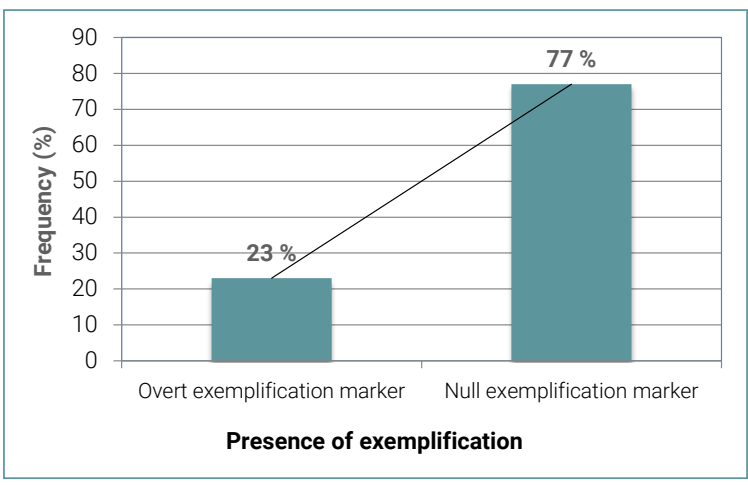

Figure 2: Presence of exemplification markers
Chen (2009): this trend was also found to be true in the writings of the learners of the present study.

\section{DISCUSSION}

In sum, first the findings of this study provide us evidence that the learners were able to follow the argumentative style of writing in that they presented claims and substantiated them using exemplification, quite in keeping with the standard conventions of academic writing in English (Hinkel 2001) and contrary to earlier findings that report underuse of exemplification in studies of Hvitfeldt (1992) and Samlley, Ruetten (2000). We also observe that the types of exemplification used are guided by the discourse requirements and writing style of the learners. So across their reports a few of the learners have used several types of exemplification; this has lent variety to writing.

Second, the learners who achieved high unity in their reports were found to use brief examples at sentence level to elaborate ideas better than learners in medium and low unity groups, who mostly used a listing technique and used brief examples at phrase level, though both the low and medium unity groups distributed the two types of exemplification quite well. These findings prove both the research questions to be true.

Lastly, we note that the learner group has not been perfect in using the exemplification technique. We observed that even though the learners used exemplification, they did not attempt to elaborate the main and supporting claims at length, but overused brief examples in many cases. The learners have underused move three or refute a claim with a counter argument and its corresponding elaboration (refer to Table 2 and Figure 1). The fact that they have presented moves one, two and four is because these are more salient moves where they introduce a claim (move one), elaborate it with information and exemplification (move two) and conclude the claim with confirming their evaluation (move four).

\section{CAN EXEMPLIFICATION HELP TO ARGUE BETTER?}

The purpose of this study was to examine whether self-assessment reports could help ESL learners argue better. From a quantitative and qualitative analysis we find that the learners were mostly aware of their current abilities (Blanche, Merino 1989), they were able to voice those as well as the growth and awareness they experienced as a result of doing the course and the self-assessment task (Paris, S. G., Paris, A. H. 2001). They could also point to their future goals and orientations that they would take from the course (McMillan, Hearn 2009; Baleghizadeh, Masoun 2014). Hence, they could make a number of claims or observations and elaborate and substantiate them with exemplification. So the use of argumentation skills was well crafted through use of appropriate topic moves and exemplification. While previous research on ESL writing shows that SL/FL learners often fail to use 
the technique of exemplification appropriately (Hvitfeld 1992; Hinkel 2001), the findings of this study give us evidence of a different kind. What could have resulted in this language gain?

Two factors could have caused this: First, the use of self-assessment report as a type of formative assessment created scope for writing development. The self-assessment report became a democratic form of assessment where the 'voices' of the test takers were heard in a non-threatening atmosphere, an idea stressed upon by Shohamy (2001) in her argumentation on the ethics and power of language testing. This might have motivated the learners to express themselves with a tone of authority or ownership to what they have written, and this may have urged them to prove their claim using exemplification. So their psychological association with the task might have made them 'notice' (Schmidt 2001) and 'pushed' them to use exemplification to present their claims convincingly (Swain 2000). In more formal academic texts, ESL learners are conscious of the fact that they need to adopt an objective style of writing, which creates 'a psychological distance' between the writer and what they express, and this may affect their writing style (Schumann 1990). This very often prevents them from voicing an opinion and justifying it persuasively. So, one implication of this study is that if learners are allowed to write in a semi-formal style, they might be able to build cogent arguments using several personal recounts as examples. The learners can then be trained to transfer and use a similar style in more formal texts like critical essays, reviews and reports as formulated by Cummins (1986) in his forceful CALP transfer hypothesis. Whether learners will be able to transfer such skills to more formal texts of course remains the subject of further study.

The second factor is based on learners' use of 'attentional mechanisms' (Robinson et al. 2012; Robinson, submitted for publication) to learn to argue convincingly. Recall that prior to writing the self-assessment reports, learners' attention was drawn towards the role of exemplification in building persuasive arguments through smaller assignments as part of a formative assessment model followed throughout the course. They were given feedback on writing style, especially on the role of exemplification in developing argumentation. These instructional inputs could have boosted the number and types of exemplification used in the self-assessment reports. It is both difficult and unwise to claim that one self-assessment report can dramatically change the writing style of learners. Rather it is more plausible to say that the learners, by attempting to assess the course content and their language learning skills, were initiated into building arguments and used the technique of exemplification So, a second implication of this study is that once the exemplification technique has been initiated in learners, it is likely that they might notice many more instances of this style and its various communicative functions while reading texts in future (Halliday, Hasan 1976; Biber et al 2004; Hinkel 2001). So, the use of exemplification technique can occur as a spiral-learning event (Bruner 1960) where learners begin to notice every instance of its occurrence and direct their attention and store this writing style in their long-term memory. Gradually this would become an automatic skill and can be used readily to argue better, following the power law of learning where practice would automatize comprehension and production (Ellis, Schmidt 1998; DeKeyser 2007). However, the validity of this claim has to be corroborated through further research.

\section{PEDAGOGICAL IMPLICATIONS}

To conclude, our method to initiate adult ESL learners into employing argumentation skills by using exemplification met with tenable success. The findings presented in this study are to provide an idea for teachers to use this form of alternative assessment to further the language learning goals of adult ESL/EFL learners.

However, a limitation of the study is the group number was small. The small number was because it was an in-depth study with descriptive and qualitative analysis of the instances of exemplifications. Another limitation is that since this is an exploratory classroom-based study with a thrust on qualitative analysis, the statistical analysis is to give readers an overview of the occurrences of types of exemplification and then explain the presence through formal analysis of authentic written language as used by the learners. So, this paper does not make any generalizable claims from the statistical analysis. It rather focuses on the qualitative analysis of language learning gains afforded by writing self-assessment reports, a feature that has not been documented before.

Further research needs to be conducted to examine the long-term writing benefits in larger groups of ESL/EFL learners and in various linguistic and organizational features and across diverse text types in academic writing. Nevertheless, what we can conclude from this classroom-based assessment and qualitative study of student writing knowledge as found through semi-formal narrative self-assessment reports is that ESL/EFL learners can be made to pay conscious attention to features of academic writing to experience 'a pushed output' phenomena to improve upon their argumentation techniques as well as build content by way of using exemplification. So task-based features can push output in a manner that learners are able to produce argumentation in a well-formed manner. This specific attention to writing style, to the development of argumentation and content, can be further applied to other aspects of academic writing, like building stance and elaborating upon it or summarizing text-based arguments to build inter-textuality in one's writing and so on. Thus, if ESL/EFL teachers help learners attend to specific features of academic writing and give real life tasks to build on those features, it would motivate the learners and help them develop writing knowledge required for independent writing in higher academia. 
Funding: The author did not receive any funding for this research.

Acknowledgments: The author would like to thank all the learners for their participation and the support of Professor Shruti Sircar to review and comment on the paper prior to its submission.

Conflicts of Interest: The author declares no conflict of interest.

\section{REFERENCES}

Bachman, L. F., 2000. Learner-directed assessment in ESL. In Ekbatani G., Pierson H. (Eds.), Learner-directed assessment in ESL. New Jersey: Lawrence Erlbaum Associates, Inc, pp. ix-xii.

Baleghizadeh, S., Masoun, A., 2014. Effect of self-assessmnet on EFL learners goal orientations. Iranian Journal of Applied Linguistics, 17(1), 25-58.

Biber, D., Conrad, S., Cortes, V., 2004. If you look at ...: Lexical bundles in university teaching and textbooks Applied Linguistics 25(3), 371-405.

Birjandi, P., Hadidi Tamjid, N., 2012. The role of self-, peer and teacher assessment in promoting Iranian EFL learners' writing performance. Assessment \& Evaluation in Higher Education, 37(5), 513-533.

Birjandi, P., Siyyari, M. 2010. Self-assessment and Peer-assessment: A Comparative Study of Their Effect on Writing Performance and Rating Accuracy. Iranian Journal of Applied Linguistics, 13(1), 23-45.

Blanche, P., Merino, B. J. 1989. Self-assessment of foreign-language skills: Implications for teachers and researchers. Language Learning, 39(3), 313-349.

Boud, D., Falchikov, N. 1989. Quantitative studies of student self-assessment in higher education: A critical analysis of findings. Higher Education, 18, 529-549.

Brinkmann, S., 2018. Teachers' beliefs and educational reform in India: from 'learner-centred' to 'learning-centred' education, Comparative Education, 55(1), 9-29.

Butler, G. Y., Lee, J. 2010. The effects of self-assessment among young learners of English. Language Testing, 27(1), 5-31.

Bruner, J., 1960. The process of education. Cambridge, MA: The President and Fellows of Harvard College.

Chen, Y. M., 2008. Learning to self-assess oral performance in English: A longitudinal case study. Language Teaching Research, 12(2), 235-262.

Clarke, P., 2003. Culture and Classroom Reform: the case of the District Primary Education Project, India. Comparative Education, 39(1), 27-44.

Cheng. F., Chen, Y., 2009. Taiwanese argumentation skills: Contrastive rhetoric perspective. Taiwan International ESP Journal, 1(1), 23-50.

Connor, U., 1996. Contrastive rhetoric: Cross-cultural aspects of second-language writing. New York: Cambridge University Press.

Cummins, J., 1986. Linguistic interdependence: A central principle of bilingual education. In J. Cummins, and M. Swain. (Eds.). Bilingualism in education: Aspects of theory, research and practice. London \& New York: Longman.

DeKeyser, R., 2007. Skill acquisition theory. In VanPatten, B., Williams, J. (eds), Theories in second language acquisition: an introduction. Mahwah, NJ: Lawrence Erlbaum., pp. 97-112.

de Saint-Léger, D., 2009. Self-assessment of speaking skills and participation in a foreign language class. Foreign Language Annals, 42(1), 158-178.

Dörnyei, Z., 2007. Research methods in applied linguistics. Oxford: Oxford University Press.

Ellis, N. C., Schmidt, R., 1998. Rules or associations in the acquisition of morphology? The frequency by regularity interaction in human and PDP learning of morphosyntax. Language and Cognitive Processes, 13(2-3), 307-336.

Falchikov, N., Boud, D., 1989. Student self-assessment in higher education: A meta-analysis. Review of Educational Research, 59(4), 330-395.

Halliday, M. A. K., Hasan, R., 1976. Cohesion in English. London: Longman.

Hargreaves, A., Earl, L., Schmidt, M., 2001. Perspectives on alternative assessment reform. American Educational Research Journal, 39(1), 69-95.

Hinkel, E., 2001. Giving examples and telling stories in academic essays. Issues in Applied Linguistics, 12(1), 149-170.

Hvitfeld, C., 1992. Oral orientations in ESL academic writing. College ESL, 2(1), 29-39.

Matsuno, S., 2009. Self-, peer-, and teacher-assessments in Japanese university EFL writing classrooms. Language Testing, 26(1), 75-100.

McMillan, J. H., Hearn, J., 2009. Student Self-assessment: The key to stronger motivation and higher achievement. Educational Horizons, 87(1), 40-49.

Meganathan, R., 2015. English language education situation in India: Pedagogical perspectives. The Journal of English as an International Language, 10(1), 48-66.

Oscarson, M., Apelgren, B. M., 2011. Mapping language teachers' conceptions of student assessment procedures in relation to grading: A two-stage empirical inquiry. Fuel and Energy Abstracts, 39(1), 2-16.

Paquot, M., 2008. Exemplification in learner writing: a cross-linguistic perspective. In Meunier, F., Granger S. (Eds.), Phraseology in Foreign Language Learning and Teaching. John Benjamins Publishing Company., pp. 101-119.

Paris, S. G., Paris, A. H., 2001. Classroom applications of research on self- regulated learning. Educational Psychologist, 36(2), 89-101.

Robinson, P., Mackey, A., Gass, S., Schmidt, R., 2012. Attention and awareness in second language acquisition. In Gass, S., Mackey, A. (Eds.), The Routledge handbook of second language acquisition. New York: Routledge, pp. 247-267. 


\section{Mukhopadhyay}

Sadek, N., 2013. Self-assessment and the process of ESL writing. TESOL Connections, available at: <http://newsmanager.commpartners.com/tesolc/ issues/2013-03-01/5.html>

Schumann, J. H., 1990. Extending the scope of the acculturation/pidginization hypothesis. TESOL Quarterly, 24(4), 667-684.

Schmidt, N., 2001. Attention. In P. Robinson (ed.), Cognition \& second language instruction, pp. 3-33, New York: Cambridge University Press.

Swain, M., 2000. The output hypothesis and beyond: mediating acquisition through collaborative dialogue. In Lantolf J. P. (ed.), Sociocultural theory and second language learning, New York: Oxford University Press, 97-114.

Shohamy, E., 2001. The power of tests: A critical perspective on the uses of language tests. London: Longman.

Smalley, R., Ruetten, M., 2000. Refining composition skills (5th Ed.). Boston: Heinle \& Heinle.

Watson Todd, R., Thienpernpool, P., Keyuravong, S., 2004 Measuring the coherence of writing using topic-based analysis. Assessing Writing, 9(2), 85-104.

\section{END NOTES}

1 However, this sequence is not universal, and it has been shown through discourse analysis that Japanese (Hinkel 2001) and Chinese (Paquot 2008) learners prefer to present the examples/anecdotes/evidence first and then round them up in the form of a claim. The difference is primarily in the way the claim and the evidence are structured: this does not call into question the components of an argument.

2 Proper consent has been sought from the concerned human subjects who have participated in this study.

3 An alphanumeric system was used to refer to scripts.

4 For all statistical tests we used an alpha level of .05.

Return to front page $\uparrow$ 